\title{
Mecanismos de controle da murcha-de-esclerócio e promoção de crescimento em tomateiro mediados por rizobactérias
}

\author{
Gabriela Queiroz Pelzer ${ }^{1}$, Bernardo A. Halfeld-Vieira ${ }^{2}$, Kátia de Lima Nechet ${ }^{2}$, Giovanni Ribeiro de Souza ${ }^{1}$, \\ Jerri Édson Zilli ${ }^{1}$ \& Liamara Perin ${ }^{3}$
}

${ }^{1}$ Embrapa Roraima, 69301-970, Boa Vista, RR, Brasil; ${ }^{2}$ Embrapa Meio Ambiente, 13820-000, Jaguariúna, SP, Brasil; ${ }^{3}$ Instituto Federal de Educação, Ciência e Tecnologia de Sergipe, Campus Glória, 49680-000, Nossa Senhora da Glória, SE, Brasil

Autor para correspondência: Bernardo A. Halfeld-Vieira, e-mail: halfeld@cnpma.embrapa.br

\section{RESUMO}

Este trabalho teve por objetivo caracterizar os possíveis mecanismos de antagonismo responsáveis pelo biocontrole da murchade-esclerócio e os fatores envolvidos na promoção de crescimento de tomateiro por rizobactérias selecionadas. As rizobactérias foram caracterizadas por meio da utilização de fontes de carbono, perfil de ácidos graxos e sequenciamento do 16S rDNA amplificado, enquanto os mecanismos de biocontrole e promoção do crescimento analisados através de indicadores bioquímicos e bioensaios. As rizobactérias agruparam-se com os gêneros Agrobacterium e Kluyvera. Os resultados indicam que a competição por ferro e antibiose são os possíveis mecanismos responsáveis pela capacidade de biocontrole da murcha-de-esclerócio exercida por essas rizobactérias, assim como a produção de auxinas e a fixação biológica de nitrogênio podem explicar a promoção do crescimento das plantas. Também foram demonstradas limitações do controle biológico, em função da capacidade de competição depender do isolado de Sclerotium rolfsii e, da antibiose, da composição nutricional do meio de crescimento.

Palavras-chave: Athelia rolfsii, Sclerotium rolfsii, antibiose, auxinas, controle biológico, fixação biológica de nitrogênio, sideróforos.

\begin{abstract}
Control mechanisms of southern blight and growth promotion on tomato mediated by rhizobacteria

This study was conducted to elucidate the possible mechanisms responsible for the biocontrol of southern blight and the elements involved in tomato growth promotion by selected rhizobacteria. The rhizobacteria were characterized by carbon source utilization, fatty acid profiles, and 16S rDNA sequencing, while biocontrol mechanisms were investigated using biochemical indicators and bioassays. The rhizobacteria clustered within Agrobacterium and Kluyvera. The results indicated that iron competition and antibiosis are mechanisms that explain the biocontrol capability of southern blight by rhizobacteria. In the same way, auxin production and biological nitrogen fixation can explain growth promotion. Limitations of biological control were demonstrated because the competition capability is strain-specific for Sclerotium rolfsii, and antibiosis depends on the nutritional composition of growth media.
\end{abstract}

Key words: Athelia rolfsii, Sclerotium rolfsii, antibiosis, auxins, biocontrol, nitrogen fixation, siderophores.

\section{INTRODUÇÃO}

Rizobactérias promotoras de crescimento de plantas (PGPR) são conhecidas por estimularem o crescimento vegetal, além de serem eficientes competidoras com organismos deletérios na região da rizosfera. Como consequência, as PGPR podem ser empregadas no controle biológico de fitopatógenos, no aproveitamento mais eficiente de fertilizantes e como rizoremediadoras, pela degradação de compostos nocivos às plantas (Bakker et al., 2007).

Dentre os mecanismos responsáveis pela promoção de crescimento vegetal por bactérias, frequentemente estão

Parte da Dissertação de Mestrado do primeiro autor. Universidade Federal de Roraima. UFRR. Boa Vista RR. 2010. envolvidos a fixação biológica de nitrogênio (Baldani \& Baldani, 2005), produção de ácido indol acético (Spaepen et al., 2009) e solubilização de fosfatos (Souchie et al., 2005). Por outro lado, os mecanismos de antagonismo direto relacionados ao controle biológico de fitopatógenos, normalmente envolvem a produção de enzimas líticas como quitinases (Kavino et al., 2010) e a produção de antibióticos difusíveis (Ahmad et al., 2008), enquanto o sequestro de ferro por sideróforos está associado tanto à promoção do crescimento quanto ao controle biológico (Glick, 1999; Ahmad et al., 2008).

Entretanto, muitas vezes a detecção da produção destes compostos e os bioensaios são utilizados como meio para seleção de rizobactérias (Ahmad et al., 2008) e os resultados promissores observados in vitro não são verificados in vivo. Nesse contexto, a investigação dos mecanismos de controle deve constituir uma etapa posterior 
ao processo de seleção, em que se determinam quais deles explicam e têm importância ao interferir no processo de infecção por um fitopatógeno, a não ser para casos em que tais mecanismos já estejam bem estabelecidos. Outros dois aspectos a serem levados em consideração são a especificidade dos mecanismos envolvidos atuarem sobre determinadas populações do patógeno e a perda da capacidade de síntese ou da atividade de metabólitos em função das condições do habitat que ocupam, o que pode levar ao insucesso do antagonista em exercer o biocontrole.

A partir de um processo de seleção in vivo de rizobactérias visando o controle da murcha-de-esclerócio em tomateiro (Barbosa, 2009), foram obtidas quatro rizobactérias que apresentaram potencial de serem empregadas como agentes de controle biológico, sem efeito deletério ao crescimento das plantas. Considerando o sítio e o modo de infecção de Sclerotium rolfsii Sacc., um fungo habitante do solo e agente causal da murcha-deesclerócio, foi formulada a hipótese de que os mecanismos diretos de antagonismo são responsáveis pela capacidade de controle exercida por estas rizobactérias. O presente trabalho teve como objetivos: identificar as rizobactérias selecionadas, investigar se mecanismos de antagonismo direto são responsáveis pelo biocontrole da murcha-deesclerócio e que fatores estão envolvidos na promoção de crescimento em tomateiro, por meio das quatro rizobactérias selecionadas in vivo para o biocontrole dessa doença.

\section{MATERIAL E MÉTODOS}

\section{Origem dos isolados}

As rizobactérias designadas RR31223, RR32238, RR33282 e RR38291, foram obtidas da rizosfera de tomateiros sadios, coletados em diferentes municípios no estado de Roraima e selecionadas dentre 274 isolados, para o controle de $S$. rolfsii na cultura do tomateiro (Barbosa, 2009). O isolado RR258 de $S$. rolfsii, obtido do pimentão (Capsicum annuum), foi utilizado durante o processo de seleção dos antagonistas em condições de casa-devegetação. Além deste, foram utilizados os isolados RR561, proveniente da cultura da melancia (Citrullus lanatus) e RR517-1, obtido da cultura da mamona (Ricinus communis). Para verificação da divergência genética entre os isolados de $S$. rolfsii foi realizado pareamento em meio de cultura BDA (batata dextrose agar), conforme Okabe \& Matsumoto (2000). Todos os isolados citados acima estão depositados na coleção de culturas da Embrapa Roraima.

\section{Identificação das rizobactérias}

\section{Perfil de ácidos graxos e Teste de Gram}

Para determinação do perfil de ácidos graxos, colônias foram repicadas para o meio agar triptona de soja (TSBA, Difco ${ }^{\mathrm{Tm}}$, Sparks, MD, USA) em placas de Petri e incubadas por $24 \mathrm{~h}$ em BOD. A metodologia para caracterização dos perfis de ácidos graxos seguiu as instruções do MIS Operating Manual (2001) que acompanha o aparelho de cromatografia gasosa da Agilent $6850 \mathrm{com}$ injetor automático e o cromatograma analisado por meio do Microbial Identification System software (Sherlock TSBA40 library; MIDI Inc., Newark, DE, USA) (Dias et al., 2009). O teste de Gram foi realizado pela solubilidade das colônias em KOH 3\% (Schaad et al., 2001).

\section{Sequenciamento da região $16 \mathrm{~S}$ rDNA}

O sequenciamento da região $16 \mathrm{~S}$ rDNA foi realizado de acordo com Videira et al. (2009). Após a montagem das sequências foram realizadas análises de similaridade utilizando o programa BLAST e o banco de sequências não redundantes do NCBI. A árvore filogenética foi elaborada por meio do software MEGA 4.1 (Tamura et al., 2007), pelo método de agrupamento da distância média UPGMA, utilizando para as comparações espécies tipo, depositadas em coleções de culturas, dos gêneros que apresentaram maior similaridade com as rizobactérias.

\section{Capacidade de metabolizar diferentes fontes de carbono}

A capacidade de utilizar diferentes fontes de carbono foi avaliada pelo uso do kit Biolog ${ }^{\circledR}$ GN2 para bactérias Gram-negativas, seguindo as recomendações do fabricante, sendo as avaliações realizadas por meio de leitora de placas ELISA, no comprimento de onda de $492 \mathrm{~nm}$, indicando a utilização de respectivas fontes de carbono pelos isolados testados.

\section{Capacidade de fixação assimbiótica de $\mathbf{N}_{2}$}

A capacidade de fixar nitrogênio atmosférico foi avaliada segundo a metodologia descrita por Estrada-de Los Santos et al. (2001), sendo utilizadas duas repetições em frascos de vidro com $5 \mathrm{~mL}$ de meio de cultura BMGM para cada rizobactéria. As amostras foram incubadas no escuro por 10 dias a $28^{\circ} \mathrm{C}$, avaliando-se a formação de película na superfície do meio.

\section{Capacidade de produção de ácido indol acético (AIA)}

Foi utilizada a metodologia descrita por Sarwar \& Kremer (1995). Os isolados foram cultivados em $5 \mathrm{~mL}$ de meio de cultura DYGS líquido com $100 \mu \mathrm{g} \mathrm{mL}^{-1}$ de triptofano por $48 \mathrm{~h}$ a $30^{\circ} \mathrm{C}$, sob agitação constante a 150 rpm. Após o período de incubação, uma alíquota de 1 $\mathrm{mL}$ da suspensão bacteriana foi centrifugada por $5 \mathrm{~min}$ a $520 \mathrm{~g}$ e $150 \mu \mathrm{L}$ do sobrenadante foram aplicados em cavidades contidas em microplaca de poliestireno com capacidade para $300 \mu \mathrm{L}$, com quatro repetições para cada rizobactéria. Sobre as amostras, foram adicionados 100 $\mu \mathrm{L}$ do reagente de Salkowsk ( $1 \mathrm{~mL}$ de $\mathrm{FeCl}_{3} .6 \mathrm{H}_{2} \mathrm{O} 0,5 \mathrm{M}$ em $50 \mathrm{~mL}$ de $\mathrm{HClO}_{4}$ a $35 \%$ ), e as placas permaneceram no escuro por $30 \mathrm{~min}$. A produção de AIA foi detectada em leitora de placas ELISA, em comprimento de onda de $492 \mathrm{~nm}$. 


\section{Capacidade de Solubilização de Fosfato de Cálcio}

A capacidade de solubilização de fosfato foi verificada em meio de cultura GL sólido (Sylvester-Bradley et al., 1982). Depois de esterilizado, e com temperatura próxima a $50^{\circ} \mathrm{C}$, foram adicionados ao meio, $50 \mathrm{~mL}$ de $\mathrm{K}_{2} \mathrm{HPO}_{4}(10 \%)$ e $100 \mathrm{~mL}$ de $\mathrm{CaCl}_{2}(10 \%)$, para formação de precipitado insolúvel de $\mathrm{CaHPO}_{4}$, sendo, em seguida, distribuído em placas de Petri. Cada isolado, foi semeado em um ponto do meio de cultura e incubado por 10 dias a $30{ }^{\circ} \mathrm{C}$ no escuro, utilizando-se quatro repetições. Após este período, foi realizada a avaliação visual para verificação da formação de halo transparente de solubilização no meio de cultura originalmente opaco, característica que indica a capacidade de solubilização de fosfato de cálcio.

\section{Produção de quitinase}

Para detecção da produção de quitinase, utilizouse meio mineral Renwick et al. (1991), em que quitina (Sigma) coloidal $0,08 \%$ foi a única fonte de carbono. Posteriormente, as rizobactérias foram semeadas em pontos distintos da superfície do meio e incubadas a $25^{\circ} \mathrm{C}$ durante 10 dias, sendo utilizadas três repetições para cada tratamento. Após o período de incubação, foi analisada a produção de quitinase constatada pela observação de um halo transparente ao redor da colônia contrastando com o restante do meio com aspecto leitoso.

\section{Produção de $\beta$-1,3-glucanase}

Para detecção da produção de $\beta$-1,3-glucanase, também foi usado o meio mineral Renwick et al. (1991), com laminarina (Sigma) a 0,5\% como a única fonte de carbono. Os isolados foram semeados no meio em distintos pontos da superfície e incubados a $25^{\circ} \mathrm{C}$ durante dez dias, sendo três repetições para cada tratamento. Após o período de incubação, a superfície do meio de cultura foi coberta com uma solução de vermelho do Congo $0,5 \%$ por $90 \mathrm{~min}$, sendo o excesso eliminado. A constatação da capacidade de produção de $\beta$-1,3-glucanase é evidenciada pela observação visual um halo laranja claro ao redor da colônia, contrastando com o restante do meio com aspecto vermelho-alaranjado.

\section{Antibiose por compostos voláteis}

Foram utilizadas placas de Petri com $85 \mathrm{~mm}$ de diâmetro, divididas em três compartimentos (Fernando et al., 2005). O primeiro compartimento de todas as placas foi preenchido commeio 523 (Kado \& Heskett, 1970) e semeadas as rizobactérias, no segundo compartimento foi adicionado o meio BDA (batata dextrose agar), onde se depositou um disco de micélio de $S$. rolfsii com $5 \mathrm{~mm}$ de diâmetro, no terceiro compartimento foi constituído pela presença ou ausência de $5 \mathrm{~g}$ de carvão ativado. Adicionalmente ao tratamento com carvão ativado, foi utilizada como testemunha adicional, placas de Petri tripartidas contendo somente o disco de micélio de $S$. rolfsii em meio BDA, em um dos compartimentos. Após o seu preparo, as placas foram fechadas com Parafilm "M" (Pechiney Plastic
Packaging) e mantidas em BOD a $25^{\circ} \mathrm{C}$, com fotoperíodo de $12 \mathrm{~h}$. A taxa de crescimento fúngico foi registrada a cada $24 \mathrm{~h}$ por 4 dias consecutivos, pela medição do diâmetro da colônia sobre o eixo que liga os dois vértices da borda do compartimento. $\mathrm{O}$ arranjo experimental foi inteiramente casualizado em arranjo fatorial, constituído por 6 repetições para cada tratamento com duas testemunhas e analisado por contraste de médias em relação às testemunhas, por meio do software SAS versão 9 (SAS Institute Inc., Cary, USA).

\section{Antibiose por difusão em meio de cultura}

As rizobactérias foram cultivadas por $48 \mathrm{~h}$ e preparada uma suspensão em água destilada esterilizada, ajustada a $\mathrm{Abs}_{540}=0,2$. Posteriormente, foram semeados, por espalhamento com uma alça de Drigalski, $100 \mu \mathrm{L}$ da suspensão em placas contendo $15 \mathrm{~mL}$ de meio 523. Após quatro dias, as células bacterianas foram mortas por meio de vapor de clorofórmio por um período de $2 \mathrm{~h}$, mantendose as placas abertas por $4 \mathrm{~h}$ para sua volatização. Uma sobrecamada de $15 \mathrm{~mL}$ de BDA foi vertida, semeando-se um disco de micélio de $S$. rolfsii, com 96 h de crescimento, no centro de cada placa. As medições diametrais das colônias foram realizadas diariamente por um período de cinco dias consecutivos. Cada tratamento foi composto por 6 repetições e o delineamento experimental foi inteiramente casualizado, sendo as taxas de crescimento analisadas por meio do proc GLM do software SAS versão 9 e do teste de Tukey a 5\% de significância.

\section{Produção de sideróforos}

Foi utilizada a metodologia descrita por Schwyn \& Neilands (1987), adaptada por Macagnan etal.(2008), em que as rizobactérias foram cultivadas, por 48 horas sob contínua agitação, em meio líquido B de King (King et al., 1954). Como controle negativo foram cultivadas as rizobactérias no mesmo meio acrescido de $2 \mu \mathrm{M}$ de $\mathrm{Fe}^{2+}$. $\mathrm{mL}^{-1}$ preparado a partir de $\mathrm{FeSO}_{4} 7 \mathrm{H}_{2} \mathrm{O}$ e esterilizado por autoclavagem. Posteriormente, as culturas bacterianas foram centrifugadas a $10.000 \mathrm{~g}$ por $20 \mathrm{~min}$ e adicionado $1 \mathrm{~mL}$ do sobrenadante a $1 \mathrm{~mL}$ da solução indicadora de Cromo Azurol S (CAS). Como controles adicionais, para comparação, foi verificada a coloração adquirida nos mesmos meios sem o cultivo de bactérias. A constatação da produção de sideróforos pelas rizobactérias foi demonstrada pela mudança de coloração da mistura de azul para amarelo-alaranjado, em um período de até 15 min.

\section{Efeito dos sideróforos no crescimento micelial de $S$. rolfsii}

Inicialmente as rizobactérias foram cultivadas por $48 \mathrm{~h}$ e posteriormente preparada uma suspensão em água destilada esterilizada ajustada a $\mathrm{Abs}_{540}=0,2$. Em seguida, $100 \mu \mathrm{L}$ da suspensão foram adicionados ao meio B de King, com e sem a adição de $2 \mu \mathrm{M}$ de $\mathrm{Fe}^{2+}$. $\mathrm{mL}^{-1}$ preparado a partir de $\mathrm{FeSO}_{4} 7 \mathrm{H}_{2} \mathrm{O}$, mantendo-se em incubação por 4 dias. Após este período as células bacterianas foram mortas por meio 
de vapor de clorofórmio por um período de $2 \mathrm{~h}$. Após $4 \mathrm{~h}$, foi vertida uma segunda camada de $15 \mathrm{~mL}$ do meio B de King, com e sem a presença de $2 \mu \mathrm{M}$ de $\mathrm{Fe}^{2+} \cdot \mathrm{mL}^{-1}$, e depositado um disco de micélio de $S$. rolfsii no centro de cada placa. As taxas de crescimento fúngico foram obtidas por meio das medições diametrais do fungo realizadas diariamente, por um período de seis dias. Cada tratamento, com exceção das testemunhas, foi composto por um isolado de rizobactéria, contendo 6 repetições cada. Os delineamentos experimentais foram inteiramente casualizados, e os dados obtidos foram analisados por meio de arranjo fatorial 5 (4 isolados + testemunha) $\times 2$ (com e sem a presença de ferro). Os valores das taxas de crescimento foram submetidos à análise de variância usando o proc GLM do software SAS versão 9 sendo utilizado para comparações de médias o teste Fisher-LSD a $5 \%$ de probabilidade.

Colonização de raízes de tomateiro e influência das rizobactérias no crescimento de plântulas de tomateiro na ausência de nutrientes exógenos

As sementes de tomateiro (Solanum lycopersicum) cv. Santa Clara foram microbiolizadas e semeadas em agarágua (Merck) 0,6\% contido em tubos de ensaio (Silva et al., 2003), incubando-se o material a $25^{\circ} \mathrm{C}$ em fotoperíodo de $12 \mathrm{~h}$. O arranjo experimental foi inteiramente casualizado, com 10 repetições para cada tratamento. Após 12 dias foi verificada a capacidade de colonização de raízes conforme Silva et al. (2003), realizada a mensuração do seu comprimento, assim como da parte aérea. Os dados obtidos foram analisados usando o proc GLM do software SAS versão 9 (SAS Institute Inc., Cary, USA) e o teste de FisherLSD a $5 \%$ de probabilidade.

\section{Capacidade de promoção de crescimento em condições de casa-de-vegetação}

As sementes de tomate foram previamente desinfestadas em etanol a $50 \%$ por $30 \mathrm{~s}$, seguido de hipoclorito de sódio a $2 \%$ por $3 \mathrm{~min}$, sendo lavadas por três vezes em água esterilizada, e em seguida embebidas em 5 $\mathrm{mL}$ da suspensão bacteriana de cada isolado ajustada em espectrofotômetro a $\mathrm{Abs}_{540}=0,3$ e mantidas em temperatura ambiente por $24 \mathrm{~h}$. Como controle foram utilizadas sementes embebidas em água destilada esterilizada. Posteriormente foram plantadas em sementeiras, contendo substrato Plantmax ${ }^{\circledR}$ e, após 14 dias, transplantadas para vasos contendo solo desinfestado com metam-sódico (Buckman Laboratórios Ltda.), ingrediente ativo precursor de isotiocianato de metila. Após 28 dias do transplantio foi mensurada a altura das plantas que, em seguida, foram removidas dos vasos. As raízes foram lavadas, secas em estufa de circulação de ar forçado a $60^{\circ} \mathrm{C}$ por 5 dias e pesadas (massa seca total, massa seca da parte aérea e raiz). $\mathrm{O}$ delineamento experimental utilizado foi inteiramente casualizado contendo 10 repetições, sendo cada repetição constituída por um vaso com uma única planta. As comparações de médias foram realizadas conforme já descrito no item anterior.

\section{RESULTADOS E DISCUSSÃO}

Foi verificada zona de aversão na região de encontro para todos os isolados de S. rolfsii quando pareados entre si, indicando que os três isolados utilizados nos bioensaios não pertencem ao mesmo grupo de compatibilidade micelial e, portanto, não são clonais (Okabe \& Matsumoto, 2000). Esta característica permitiu uma comparação não tendenciosa dos resultados envolvendo os ensaios do efeito dos sideróforos e de antibiose para os diferentes isolados do patógeno.

Todas as rizobactérias foram Gram-negativas e os isolados RR31223, RR32238 e RR33282 posicionados no gênero Agrobacterium. Este resultado coincide com o perfil de ácidos graxos obtido para as rizobactérias RR31223 e RR33282, que apresentaram, respectivamente, por este método, 77 e $87 \%$ de similaridade com o perfil de Rhizobium radiobacter (A. tumefaciens). Entretanto, para as demais, a similaridade observada pela análise do perfil de ácidos graxos foi baixa e divergente dos obtidos pelo sequenciamento da região $16 \mathrm{~S}$ rDNA, método este que permitiu posicionar taxonomicamente com maior confiabilidade as rizobactérias, quando comparadas com espécies tipo dos gêneros que apresentaram maior similaridade de sequências da região $16 \mathrm{~S}$ rDNA (Figura 1). Verificou-se, portanto, que as rizobactérias RR31223, RR32238 e RR33282 estão posicionadas dentro do gênero Agrobacterium, ou Rhizobium segundo Young (2003), enquanto o antagonista RR38291 apresenta alta similaridade com Kluyvera georgiana.

Para o metabolismo de fontes de carbono, foi observado que todas as rizobactérias metabolizaram mais de $50 \%$ dos compostos, destacando-se os isolados RR33282 e RR38291 por utilizarem 77,08\% e 73,95\% das fontes, respectivamente. Todos os isolados metabolizaram tween 40, tween 80, adonitol, L-arabinose, i-eritritol, Dfrutose, L-fucose, D-galactose, $\alpha$-D-glucose, maltose, Dmanitol, D-trealose, ácido mono-metil-ester-succínico, ácido cis-aconítico, ácido $\mathrm{D}$-galacturônico, ácido $\rho$ hidroxifenilacético, ácido itacônico, ácido $\alpha$-ceto valérico, ácido succinâmico, L-alaninamida, L-asparagina, ácido L-glutâmico, L-histidina, L-hidroxi prolina, L-leucina, Lprolina, L-treonina, ácido urocânico, inosina e glicerol. Entretanto, nenhum metabolizou $\alpha$-ciclodextrina, glicogênio, ácido acético, ácido fórmico, ácido malônico, D, L-carnitina, timidina, putrescina, 2-aminoetanol, 2, 3butanodiol e D, L- $\alpha$-glicerofosfato. Para as demais fontes, houve variação na sua utilização.

A habilidade das rizobactérias utilizarem diversas fontes de carbono representa uma vantagem ecológica importante na disputa por determinados nichos na rizosfera, em que bactérias benéficas, utilizando múltiplas fontes presentes nos exsudatos radiculares, poderiam sobressair frente a outros microrganismos e reduzir a disponibilidade de nutrientes disponíveis para um patógeno (Cavaglieri et al., 2004). Contudo, para que se possa avaliar a capacidade de competição por nutrientes entre rizobactéria e patógeno, 


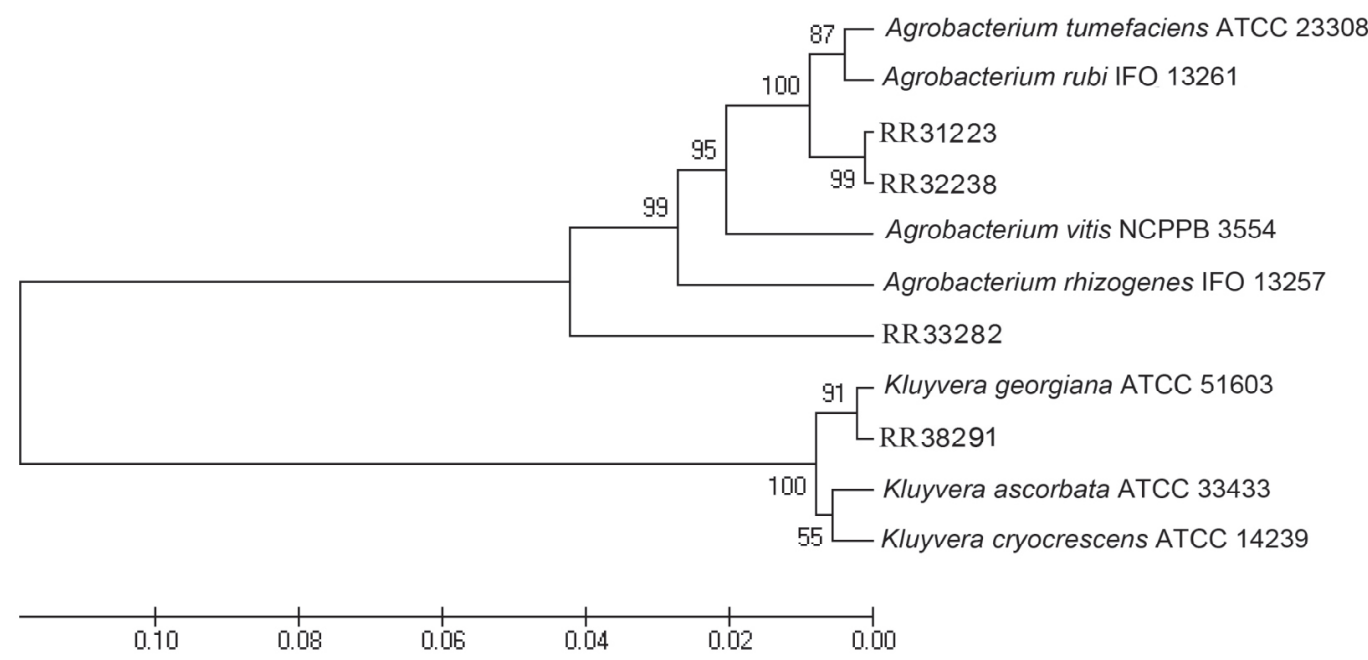

FIGURA 1 - Árvore filogenética elaborada pelo método UPGMA, das rizobactérias RR31223, RR32238, RR33282 e RR38291, selecionadas para o controle da murcha-de-esclerócio, a partir do sequenciamento do gene $16 \mathrm{~S}$ rDNA.

é necessária a definição de quais fontes são utilizadas pelos dois microrganismos.

Em relação aos mecanismos envolvidos na promoção do crescimento vegetal, foi observado que os isolados RR31223, RR32238, RR33282 apresentaram formação de película em meio de cultura semi-sólido, indicando serem capazes de fixar nitrogênio em condições microaerofílicas. Também foi detectado que os isolados RR31223 e RR33282 produziram ácido indol acético (AIA), enquanto RR33282 e RR38291 foram capazes de solubilizar fosfato de cálcio. Portanto, das quatro rizobactérias selecionadas, os isolados RR31223 e RR33282 se destacaram por apresentar resultados positivos para duas características relacionadas com a promoção de crescimento. A primeira apresentou capacidade de fixar nitrogênio e produzir AIA, enquanto a segunda apresentou, além dessas, a capacidade de solubilizar fosfato de cálcio.

A fixação biológica de nitrogênio é uma característica ainda pouco explorada na cultura do tomateiro (Mohandas, 1988; Caballero-Mellado et al., 2007), assim como a síntese e secreção de auxinas por isolados pertencentes ao gênero Agrobacterium, relatada por Tsavkelova et al. (2007). O nitrogênio fixado por bactérias associativas pode ser utilizado pelas plantas de diversas formas, enquanto o AIA estimula o crescimento vegetal e o desenvolvimento do sistema radicular, atuando no alongamento, divisão e diferenciação celular (Dobbelaere et al., 2003), estimulando também a atividade da nitrogenase (Tien et al., 1979).

Quanto à solubilização de fosfato de cálcio, um fato a ser verificado é a capacidade destas rizobactérias em facilitar a absorção de cálcio pela planta, uma vez que este nutriente está associado maior resistência de plantas à murcha-de-esclerócio. Ao cálcio é atribuída propriedade de reduzir a atividade de enzimas pectolíticas produzidas por S. rolfsii (Deacon, 1997), o que é corroborado por dados experimentais que demonstram que a maior disponibilidade deste elemento no solo está relacionada com a redução na incidência da doença (Liu et al., 2007).

A promoção de crescimento em condições de casa-de-vegetação, por meio da veiculação das bactérias pelas sementes foi verificada para os isolados RR31223 e RR32238, que se destacaram para todas as variáveis avaliadas (altura das plantas, massa seca de raiz, massa seca da parte aérea e massa seca total da planta), enquanto o isolado RR33282 apresentou um resultado intermediário (Tabela 1). O isolado RR38291, apesar de não apresentar efeito significativo para este atributo, também não ocasionou efeito deletério ao desenvolvimento das plantas.

Uma característica comum a todas as rizobactérias testadas foi a capacidade de colonizar a raiz de tomateiro, quando veiculadas por meio da microbiolização das sementes e supridas somente pelos exsudatos radiculares. A colonização radicular, além de ser considerada por alguns autores um importante critério de seleção de rizobactérias promotoras de crescimento vegetal (Silva et al., 2003) constitui uma vantagem, pois permite que se estabeleça associação desde a emissão da radícula e que estas sejam veiculadas por meio de sementes. Em relação à produção de enzimas líticas, usando a metodologia descrita, foi verificado que nenhuma das rizobactérias foi capaz de produzir quitinases ou $\beta-1,3$ glucanases, evidenciando que estas enzimas não estão relacionadas com a capacidade de biocontrole.

Os resultados também demonstraram não haver evidências da produção de compostos voláteis pelas rizobactérias, capazes de inibir o crescimento de $S$. rolfsii, já 
que não houve interação significativa entre as rizobactérias e adição de carvão ativado no terceiro compartimento, sem interferência na taxa de crescimento do patógeno nas placas tripartidas, em relação aos tratamentos controle. A ausência de inibição do crescimento micelial por compostos voláteis pode ter ocorrido devido a não produção destes elementos pelas rizobactérias testadas ou pela capacidade de detoxificação dos compostos produzidos (Osbourn, 1996).

Já a produção de compostos inibidores do crescimento de $S$. rolfsii difusíveis em meio de cultura foi detectada para o isolado RR38291, capaz de inibir totalmente o crescimento micelial dos três isolados de $S$. rolfsii testados (Tabela 2). Esta habilidade comprova a observação da formação de um halo de inibição in vitro pelo antagonista RR38291 (Barbosa, 2009). Esta rizobactéria também foi a que apresentou, com maior reprodutibilidade, redução da intensidade da doença em condições de casa-de-vegetação. Foi verificado que a síntese de substâncias antimicrobianas é importante para alguns microrganismos que atuam no controle biológico, como bactérias pertencentes aos gêneros Pseudomonas, Streptomyces, Brevibacterium e Burkholderia que são capazes de produzir fenazinas (Spaepen et al., 2009).

A produção de sideróforos foi constatada para todas as rizobactérias, com variação na capacidade de retirar íons ferro do CAS. Foi observado que o isolado RR31223 apresentou maior capacidade de indisponibilizar íons ferro, evidenciado por uma coloração amarelo-alaranjada intensa quando adicionado o CAS ao meio não suplementado com $\mathrm{FeSO}_{4} 7 \mathrm{H}_{2} \mathrm{O}$ e coloração verde clara em meio suplementado por este composto, seguido dos isolados RR32238 e
RR33282. O método para detecção da produção de sideróforos, desenvolvido por Schwyn \& Neilands (1987) se baseia no princípio de que o complexo cromo azurol + ferro, assume originalmente a coloração azul escura quando adicionado em meio de cultura. Quando retirado deste complexo o íon ferro pelo sideróforo, o corante cromo azurol muda de coloração, tendendo para o amarelo-alaranjado.

Um fato que reforça este resultado foi a interferência de algumas rizobactérias no crescimento de plântulas in vitro. Foi verificado que, quando supridas somente pelos exsudatos radiculares, as rizobactérias RR31223 e RR32238 interferem negativamente no desenvolvimento das plântulas (Tabela 3). Por outro lado, o metabólito responsável pelo mecanismo de antibiose produzido pela rizobactéria RR38291 pode ter sido responsável pela redução do crescimento nessas condições.

Entretanto, as rizobactérias capazes de quelar ferro com maior eficiência foram as que promoveram maior crescimento vegetal em condições de casa-devegetação (Tabela 1). Sabe-se que parte deste ferro pode ser disponibilizado para as plantas (Glick, 1999) e que essas moléculas estimulam a produção de auxinas (Dimkpa et al., 2008), um hormônio também produzido pelos isolados RR31223 e RR33282. Além disso, os sideróforos têm um papel indireto na promoção de crescimento, pois reduzem a toxicidade causada às plantas por metais pesados (Burd et al., 2000). Isso ocorre porque são capazes de quelar, além do ferro, elementos como $\mathrm{Al}^{3+}, \mathrm{Cd}^{2+}, \mathrm{Cu}^{2+}$ e $\mathrm{Ni}^{2+}$ (Dimkpa et al., 2008).

TABELA 1 - Efeito de rizobactérias selecionadas para o controle da murcha-de-esclerócio, causada por Sclerotium rolfsii, na promoção de crescimento de tomateiro, em condições de casa-de-vegetação

\begin{tabular}{lcccc}
\hline \hline Rizobactéria & $\begin{array}{c}\text { Altura } \\
(\mathbf{c m})\end{array}$ & $\begin{array}{c}\text { Massa seca da } \\
\text { raiz (g) }\end{array}$ & $\begin{array}{c}\text { Massa seca da } \\
\text { parte aćrea (g) }\end{array}$ & $\begin{array}{c}\text { Massa seca total da } \\
\text { planta (g) }\end{array}$ \\
\hline RR31223 & $36,60 \mathrm{a}$ & $0,83 \mathrm{ab}$ & $1,57 \mathrm{a}$ & $1,79 \mathrm{a}$ \\
RR32238 & $35,30 \mathrm{a}$ & $0,89 \mathrm{a}$ & $1,46 \mathrm{ab}$ & $1,72 \mathrm{ab}$ \\
RR33282 & $31,40 \mathrm{ab}$ & $0,74 \mathrm{abc}$ & $1,33 \mathrm{abc}$ & $1,52 \mathrm{abc}$ \\
RR38291 & $32,60 \mathrm{ab}$ & $0,67 \mathrm{bc}$ & $1,19 \mathrm{bc}$ & $1,38 \mathrm{bc}$ \\
Testemunha & $28,50 \mathrm{~b}$ & $0,62 \mathrm{c}$ & $1,14 \mathrm{c}$ & $1,30 \mathrm{c}$ \\
\hline
\end{tabular}

Médias seguidas com mesma letra não diferem entre si pelo teste Fisher-LSD a $5 \%$.

TABELA 2 - Efeito de rizobactérias selecionadas para o controle da murcha-de-esclerócio, na taxa de crescimento micelial (cm.dia-1) de três isolados de Sclerotium rolfsii, por meio da difusão de compostos em meio de cultura

\begin{tabular}{lccc}
\hline \hline Rizobactéria & S. rolfsii RR258 & S. rolfsii RR517-1 & S. rolfsii RR561 \\
\hline RR31223 & $1,50 \mathrm{a}$ & $2,52 \mathrm{a}$ & $1,90 \mathrm{a}$ \\
RR32238 & $1,51 \mathrm{a}$ & $2,47 \mathrm{a}$ & $1,67 \mathrm{a}$ \\
RR33282 & $1,44 \mathrm{a}$ & $2,67 \mathrm{a}$ & $2,07 \mathrm{a}$ \\
RR38291 & $0,00 \mathrm{~b}$ & $0,00 \mathrm{~b}$ & $0,00 \mathrm{~b}$ \\
Testemunha & $1,19 \mathrm{a}$ & $2,67 \mathrm{a}$ & $2,05 \mathrm{a}$ \\
\hline
\end{tabular}

Médias das taxas de crescimento micelial seguidas com mesma letra não diferem entre si pelo teste Tukey a $5 \%$. 
A capacidade de rizobactérias dos gêneros Kluyvera e Agrobacterium em produzir sideróforos já foi relatada por outros autores (Burd et al., 2000; Oger et al., 2001; Das et al., 2007). Já os resultados do efeito da produção dos sideróforos no crescimento dos três isolados de $S$. rolfsii evidenciam que a rizobactéria RR31223 teve maior capacidade de indisponibilizar ferro para o patógeno, pois houve supressão significativa do crescimento micelial dos três isolados de $S$. rolfsii, mesmo com suplementação por ferro (Tabela 4), concordando com os resultados descritos anteriormente.

Para as demais houve variação nos resultados. A rizobactéria RR32238 inibiu o crescimento dos isolados RR258 e RR561, mantendo sua atividade mesmo com o meio suplementado por ferro, enquanto a rizobactéria RR33282, apresentou efeito inibitório para os isolados RR561 e RR517-1, porém, a adição de ferro ao meio de cultura ocasionou a perda da capacidade de inibição (Tabela 4). Para a rizobactéria RR38291, foi verificada capacidade de inibição significativa apenas para o crescimento do isolado RR258. A contribuição de sideróforos, em adição ao mecanismo de antibiose, foi evidenciada por uma menor taxa de crescimento micelial do patógeno no meio de cultura sem suplementação de ferro, quando comparado ao tratamento em que houve suplementação por este íon.

Apesar de alguns autores considerarem que as pioverdinas são responsáveis pelo biocontrole de $S$. rolfsii exercido por Pseudomonas (Ganesan \& Gnanamanickam, 1987; Manwar et al., 2003), os resultados aqui encontrados indicam que o efeito do sideróforo produzido pelas rizobactérias na supressão do crescimento fúngico é dependente do isolado do patógeno desafiante. Isso pode ocorrer devido à capacidade de produção destas moléculas pelos isolados de $S$. rolfsii, assim como ocorre em outros fungos como Trichoderma, Fusarium e Aspergillus (Renshaw et al., 2002; Das et al., 2007). Por conseguinte, a eficiência de cada microrganismo em quelar íons ferro constitui fator que pode estar diretamente relacionado com a capacidade de biocontrole. Também deve-se destacar que a perda da capacidade de antibiose pela rizobactéria RR38291 para os isolados RR517-1 e RR561 de $S$. rolfsii em meio B de King indica que, dependendo da disponibilidade de nutrientes, o composto inibitório pode não exercer sua atividade, de acordo com o isolado do patógeno.

Portanto, os resultados indicam que a competição por ferro e antibiose por meio de compostos inibitórios difusíveis podem explicar a capacidade de biocontrole dos isolados selecionados e são mecanismos importantes no controle da murcha-de-esclerócio, assim como a produção de auxinas e fixação biológica de nitrogênio para a promoção do crescimento. Entretanto, o fato da capacidade de competição por ferro pelos sideróforos produzidos pelas rizobactérias ser dependente do isolado de $S$. rolfsii e do efeito de antibiose poder ser perdido com a mudança da composição do meio de cultura, fornecem embasamento para explicar as causas do insucesso de antagonistas no controle de doenças em determinadas situações, já que muitos fatores influenciam na sua eficácia, devendo-se considerar as limitações do controle biológico por meio de antagonistas selecionados.

TABELA 3 - Efeito de rizobactérias selecionadas para o controle da murcha-de-esclerócio, causada por Sclerotium rolfsii, no crescimento da parte aérea e radicular de plântulas de tomateiro em meio agar-água

\begin{tabular}{lcc}
\hline \hline Rizobactéria & $\begin{array}{c}\text { Comprimento do } \\
\text { epicótilo }(\mathbf{c m})\end{array}$ & $\begin{array}{c}\text { Comprimento da } \\
\text { radícula }(\mathbf{c m})\end{array}$ \\
\hline RR31223 & $4,54 \mathrm{bc}$ & $4,90 \mathrm{bc}$ \\
RR32238 & $3,34 \mathrm{c}$ & $4,29 \mathrm{~cd}$ \\
RR33282 & $7,91 \mathrm{a}$ & $5,77 \mathrm{a}$ \\
RR38291 & $5,80 \mathrm{~b}$ & $3,93 \mathrm{~d}$ \\
Testemunha & $8,60 \mathrm{a}$ & $5,59 \mathrm{ab}$ \\
\hline
\end{tabular}

Médias seguidas com mesma letra não diferem entre si pelo teste Fisher-LSD a $5 \%$.

TABELA 4 - Efeito da produção de sideróforos por rizobactérias selecionadas para o controle da murcha-de-esclerócio, causada por Sclerotium rolfsii, na taxa de crescimento micelial $\left(\mathrm{cm} \cdot \mathrm{dia}^{-1}\right)$ de três isolados de Sclerotium rolfsii

\begin{tabular}{|c|c|c|c|c|c|c|}
\hline \multirow[t]{3}{*}{ Rizobactéria* } & \multicolumn{6}{|c|}{ Sclerotium rolfsii } \\
\hline & \multicolumn{2}{|c|}{ Isolado RR258 } & \multicolumn{2}{|c|}{ Isolado RR517-1 } & \multicolumn{2}{|c|}{ Isolado RR561 } \\
\hline & Sem $\mathrm{Fe}^{++}$ & $\mathrm{Com} \mathrm{Fe} \mathrm{Fe}^{++}$ & Sem $\mathrm{Fe}^{++}$ & $\mathrm{Com} \mathrm{Fe} \mathrm{Fe}^{++}$ & Sem $\mathrm{Fe}^{++}$ & $\mathrm{Com} \mathrm{Fe}$ \\
\hline RR31223 & $0,22 \mathrm{Ba}$ & $0,00 \mathrm{Ca}$ & $0,00 \mathrm{Bb}$ & $0,73 \mathrm{Ba}$ & $0,54 \mathrm{Db}$ & $1,11 \mathrm{Ca}$ \\
\hline RR 32238 & $0,00 \mathrm{Ba}$ & $0,19 \mathrm{Ca}$ & $0,72 \mathrm{Ab}$ & $1,13 \mathrm{Aa}$ & $1,01 \mathrm{BCa}$ & $1,18 \mathrm{BCa}$ \\
\hline RR33282 & $1,00 \mathrm{Aa}$ & $0,71 \mathrm{Ba}$ & $0,10 \mathrm{Bb}$ & $1,13 \mathrm{Aa}$ & $0,87 \mathrm{Cb}$ & $1,32 \mathrm{ABa}$ \\
\hline RR38291 & $0,13 \mathrm{Bb}$ & $0,49 \mathrm{Ba}$ & $0,68 \mathrm{Ab}$ & $1,12 \mathrm{Aa}$ & $1,13 \mathrm{ABa}$ & $1,30 \mathrm{ABCa}$ \\
\hline Testemunha & $0,97 \mathrm{Aa}$ & $1,15 \mathrm{Aa}$ & $0,94 \mathrm{Ab}$ & $1,11 \mathrm{Aa}$ & $1,34 \mathrm{Aa}$ & $1,38 \mathrm{Aa}$ \\
\hline
\end{tabular}

*cultivadas em meio B de King, com e sem suplementação por sulfato ferroso

Médias das taxas de crescimento micelial seguidas com mesma letra não diferem entre si pelo teste Fisher-LSD a $5 \%$, onde: letras minúsculas representam comparações no sentido da linha e letras maiúsculas representam comparações no sentido da coluna. 


\section{AGRADECIMENTOS}

Ao Conselho Nacional de Desenvolvimento Científico e Tecnológico - CNPq pelos recursos financeiros (Proc. 471601/2009-8 e 554022/2006-0) e pela concessão de bolsa de produtividade em pesquisa concedida a Bernardo A. Halfeld-Vieira (Proc. 303081/2007-4). Agradecemos aos doutores Jean Luiz Simões de Araújo e Itamar Soares de Melo, pelo auxílio na identificação das rizobactérias.

\section{REFERÊNCIAS BIBLIOGRÁFICAS}

Ahmad F, Ahmad I, Khan MS (2008) Screening of free-living rhizospheric bacteria for their multiple plant growth promoting activities. Microbiological Research 163:173-181.

Bakker PAHM, Raaijmakers JM, Bloemberg G, Hofte M, Lemanceau P, Cooke BM (Eds.) (2007) New Perspectives and Approaches in Plant Growth-Promoting Rhizobacteria Research. Dordrecht. Springer.

Baldani JI, Baldani VLD (2005) History on the biological nitrogen fixation research in graminaceous plants: special emphasis on the Brazilian experience. Anais da Academia Brasileira de Ciências 77:549-579.

Barbosa RNT (2009) Seleção de rizobactérias visando o controle biológico da murcha-de-esclerócio em tomateiro (Solanum lycopersicum L.). Dissertação de Mestrado. Universidade Federal de Roraima UFRR. Boa Vista RR.

Burd GI, Dixon DG, Glick BR (2000) Plant growth-promoting bacteria that decrease heavy metal toxicity in plants. Canadian Journal of Microbiology 46:237-245.

Caballero-Mellado J, Onofre-Lemus J, Estrada-de los Santos P, Martínez-Aguilar L (2007) The tomato rhizosphere, an environment rich in nitrogen-fixing Burkholderia species with capabilities of interest for agriculture and bioremediation. Applied and Environmental Microbiology 73:5308-5319.

Cavaglieri L, Passone A, Etcheverry M (2004) Screening procedures for selecting rhizobacteria with biocontrol effects upon Fusarium verticillioides growth and fumonisin B1 production. Research in Microbiology 155:747-754.

Das A, Prasad R, Srivastava A, Giang PH, Bhatnagar K, Varma A (2007) Fungal siderophores: structure, functions and regulation. In: Varma A, Chincholkar SB (Eds.) Microbial Siderophores. Berlin. Springer Verlag. pp. 1-40.

Deacon JW (1997) Modern Mycology. 3rd Ed. Cambridge. Blackwell Science.

Dias ACF, Andreote FD, Dini-Andreote F, Lacava PT, Sá ALB, Melo IS, Azevedo JL, Araújo WL (2009) Diversity and biotechnological potential of culturable bacteria from Brazilian mangrove sediment. World Journal of Microbiology and Biotechnology 25:1305-1311.

Dimkpa CO, Svatos A, Dabrowska P, Schmidt A, Boland W, Kothe E (2008) Involvement of siderophores in the reduction of metal-induced inhibition of auxin synthesis in Streptomyces spp. Chemosphere 74:19-25.

Dobbelaere S, Vanderleyden J, Okon Y (2003) Plant growth- promoting effects of diazotrophs in the rhizosphere. Critical Reviews in Plant Sciences 22:107-149.

Estrada-de los Santos P, Bustillos-Cristales R, Caballero-Mellado J (2001) Burkholderia a genus rich in plant-associated nitrogen fixers with wide environmental and geographic distribution. Applied and Environmental Microbiology 67:2790-2798.

Fernando WGD, Ramarathanam R, Krishnamoorthy AS, Savchuk SC (2005) Identification and use of potential bacterial organic antifungal volatiles in biocontrol. Soil Biology and Biochemistry 37:955-964.

Ganesan P, Gnanamanickam SS (1987) Biological control of Sclerotium rolfsii Sacc. in peanut by inoculation with Pseudomonas fluorescens. Soil Biology and Biochemistry 19:35-38.

Glick BR, Patten CL, Holguin G, Penrose DM (1999) Biochemical and Genetic Mechanisms used by Plant Growth Promoting Bacteria. London. Imperial College Press.

Kado CI, Heskett MG (1970) Selective media for isolation of Agrobacterium, Corynebacterium, Erwinia, Pseudomonas and Xanthomonas. Phytopathology 60:969-979.

Kavino M, Harish S, Kumar N, Saravanakumar D, Samiyappan R (2010) Effect of chitinolytic PGPR on growth, yield and physiological attributes of banana (Musa spp.) under field conditions. Applied Soil Ecology 45:71-77.

King EO, Ward MK, Raney DE (1954) Two simple media for the demonstration of pyocyanin and fluorescein. Journal of Laboratory and Clinical Medicine 44:301-307.

Liu B, Gumpertz ML, Hu S, Ristaino JB (2007) Long-term effects of organic and synthetic soil fertility amendments on soil microbial communities and the development of southern blight. Soil Biology and Biochemistry 39:2302-2316.

Macagnan D, Romeiro RS, Pomella AWV, de Souza JT (2008) Production of lytic enzymes and siderophores, and inhibition of germination of basidiospores of Moniliophthora (ex Crinipellis) perniciosa by phylloplane actinomycetes. Biological Control 47:309-314.

Manwar AV, Khandelwal SR, Chaudhari BL, Meyer JM, Chincholkar SB (2004) Siderophore production by a marine Pseudomonas aeruginosa and its antagonistic action against phytopathogenic fungi. Applied Biochemistry and Biotechnology 118:243-251.

Mohandas S (1988) Nitrogen fixation in tomato (Lycopersicon esculentum Mill ‘Pusa Ruby'). Plant and Soil 107:219-225.

Oger R, Lopez M, Farrand SK (2001) Iron-binding compounds from Agrobacterium spp: biological control strain Agrobacterium rhizogenes K84 produces a hydroxamate siderophores. Applied and Environmental Microbiology 67:654-664.

Okabe I, Matsumoto N (2000) Population structure of Sclerotium rolfsii in peanut fields. Mycoscience 41:145-148.

Osbourn AE (1996) Preformed antimicrobial compounds and plant defense against fungal attack. The Plant Cell 8:1821-1831.

Renshaw JC, Robson GD, Trinci APJ, Wiebe MG, Livens FR, Collison D, Taylor RJ (2002) Fungal siderophores: structures, functions and applications. Mycological Research 10:1123-1142.

Renwick A, Campbell R, Coe S (1991) Assessment of in vitro screening systems for potential biocontrol agents of Gaeumannomyces graminis. Plant Pathology 40:524-532. 
Sarwar M, Kremer RJ (1995) Determination of bacterially derived auxins using a microplate method. Letters in Applied Microbiology 20:282-285.

Schaad NW, Jones JB, Chun W (Eds.) (2001) Laboratory Guide for Identification of Plant Pathogenic Bacteria. 3rd Ed. Saint Paul MN. APS Press.

Schwyn B, Neilands JB (1987) Universal chemical assay for the detection and determination of siderophores. Analytical Biochemistry 160:47-56.

Silva HSA, Romeiro RS, Mounteer A (2003) Development of a root colonization bioassay for rapid screening of rhizobacteria for potential biocontrol agents. Journal of Phytopathology 151:42-46.

Souchie EL, Azcón R, Barea JM, Saggin-Júnior OJ, Silva EMR (2005) Solubilização de fosfatos em meios sólido e líquido por bactérias e fungos do solo. Pesquisa Agropecuária Brasileira 40:1149-1152.

Spaepen S, Vanderleyden J, Okon O (2009) Plant growth-promoting actions of rhizobacteria. Advances in Botanical Research 51:283320 .

Sylvester-Bradley R, Askawa N, Latorraca S, Magalhães FMM, Oliveira LA, Pereira RM (1982) Levantamento quantitativo de microrganismos solubilizadores de fosfatos na rizosfera de gramíneas e leguminosas forrageiras da Amazônia. Acta Amazonica 12:12-22.

Tamura K, Dudley J, Nei M, Kumar S (2007) MEGA4: Molecular Evolutionary Genetics Analysis (MEGA) software version 4.0. Molecular Biology and Evolution 24:1596-1599.

Tien TM, Gaskins MH, Hubbell DH (1979) Plant growth substances produced by Azospirillum brasilense and their effect on the growth of pearl millet (Pennisetum americanum L.). Applied and Environmental Microbiology 37:1016-1024.

Tsavkelova EA, Cherdyntseva TA, Botina SG, Netrusov AI (2007) Bacteria associated with orchid roots and microbial production of auxin. Microbiological Research 162:69-76.

Videira SS, Araújo JLS, Rodrigues LS, Baldani VLD, Baldani JI (2009) Occurrence and diversity of nitrogen-fixing Sphingomonas bacteria associated with rice plants grown in Brazil. FEMS Microbiology Letters 293:11-19.

Young JM, Kuykendall LD, Martínez-Romero E, Kerr A, Sawada H (2003) Classification and nomenclature of Agrobacterium and Rhizobium - a reply to Farrand et al. (2003). International Journal of Systematic and Evolutionary Microbiology 53:1689-1695.

TPP 128 - Recebido 31 Maio 2010 - Aceito 13 Dezembro 2010 Editor de Seção: Marisa A.S.V. Ferreira 